\title{
COMPARISON OF TWO DIFFERENT TRANSPORT MODELS TO PREDICT SEDIMENT TRANSPORT: SIMIYU RIVER, TANZANIA, CASE STUDY
}

\author{
Mwanuzi Fredrick \\ Water Resources Engineering Department, University of Dar es Salaam \\ Box 35131 Dar Es Salaam fmwanuzi@yahoo.com
}

\begin{abstract}
$\mathbf{T}$ his paper presents the results of a study which focused at the spatial and temporal characteristics of sediment transport and deposition in the main river channels and floodplains. Two different numerical models were used to simulate stream flow and to analyze sediment transport and deposition in the river channels: (1) the SMS modules RMA2 and SED2D and (2) the SCALDIS model developed at the Free University of Brussels. Both numerical models contain a two-dimensional hydrodynamic module and a sediment transport module, allowing simulation of stream flow and sediment transport processes in river channels. However, they differ in the following aspects: SMS based sediment transport is decoupled from the hydrodynamic module while SCALDIS is coupled model where the hydrodynamic and transport are run in real time. Both models were applied at the downstream section of the Simuyu River, which is located at the southeast of Lake Victoria. The models were independently calibrated with a typical flood year 1967/68 and then compared.
\end{abstract}

Both model results indicate that the temporal variability of total sediment deposition during a flood event was strongly tied to the sediment inflow concentrations. The comparison of both model results indicates that SCALDIS is easier to calibrate as compared with SMS based sediment transport. The SMS modules require detailed information about a large number of model parameters, which are difficult to obtain in remote areas. The SCALDIS model is less input demanding, and the only sensitive parameter is the Manning's coefficient, which can be estimated based on expert knowledge and limited field measurements.

Key word: SCALDIS, SMS, Model, Sediment transport, FRIEND/NILE, Hydrodynamic

\section{INTRODUCTION}

The main processes determining the transport behavior of fine sediments are the availability of sediment, water movement and sedimentary processes such as flocculation, consolidation and erosion (Van Leussen, 1991). Hence, to predict the movement of sediments, a robust numerical model capable of simulating sediment transport processes and compute sediment balances is required.

Transportation of sediments by water depends on many factors such as the characteristics of water as a transporting medium e.g. density and viscosity, the characteristics of the transportable materials e.g. size, shape and specific gravity, and the lamina sublayer formed on the riverbed. Many procedures have been developed for predicting sediment transport rates (ASCE, 1975). Some of the formulae and procedures e.g. the Schoklitsch, Maver-Peter and Mueller, and Haywood formulae, are appreciable to only bedload transport, while other formula like the Duboys formula, the Einstein bedload function, Engelund-Hansen and the Colby procedures are for total sediment load. The total sediment load is defined by the American Geophysical Union as the summation of suspended load, which is the material moving in suspension in the fluid by turbulent fluctuation (Garde and Ranga Raju, 1985), the bedload, which is defined as the coarse material moving on or near the bed of the river by rolling, sliding or saltation; and wash load, which is the part of the sediment load composed of colloidal particles.

The entrainment, transport, and subsequent deposition of sediment by the stream flow are highly dependent on the properties of the sediment. Particularly, the size, shape, specific weight and size distribution of the sediment influences the rate and pattern of sediment 
processes in the river channels and reservoirs (ASCE, 1975).

The most studied of all properties of sediment on entrainment, transport and deposition is probably the particle size. Size, as a particle characteristic, has been found to describe sediment deposits adequately for many practical purposes (ASCE, 1975). However, different size classification system, e.g. the Wenworth's are in use. Each of them has been developed by various organizations to meet specific demands. Furthermore, various terminologies e.g. sieve diameter, sedimentation diameter and nominal diameter are used to characterize the size of sediment particles (ASCE, 1975; Emmanuel, 2000).

From this overview, it is clear that different approaches exist to model sediment entrainment, transport and deposition in river channels and reservoirs; and that each approach uses specific transport laws. The objective of this study is to compare the results of two different models used to simulate stream flow and sediment transport and deposition in a remote area where limited data are available. The lower reach of the Simuyu River, located in the northern part of Tanzania and draining into the Victoria Lake was selected as a case-study. In this case-study, two models were applied to analyze stream flow and sediment transport: (1) the twodimensional modules RMA2 and SED2D of the SMS software and (2) the SCALDIS model developed by the Free University of Brussels. Both models were independently calibrated and validated by using measured stream profiles, discharge and sediment load data for the downstream section of the Simiyu River in Tanzania. The simulation was done for an a typical flood of 1967/68, which is representative for a normal flood event during the rainy season.

\section{MATERIALS AND METHODS}

\section{STUDY AREA}

The Simiyu catchment is located in the southwest of Lake Victoria in the northern part of Tanzania (Fig. 1). Simiyu is the main river in the catchment, followed by the Duma River. The annual rainfall ranges between 700 and $1000 \mathrm{~mm}$. The rainfall regime is bimodal: the first short rainy season is from November to December, and a second longer rainy season is from March till May. The average temperature ranges between 22.5 and $23.7{ }^{\circ} \mathrm{C}$. Sandy loam soil covers about $60 \%$ of the catchment. About $70 \%$ of the catchment is used for agriculture, and is covered by farming land, grassland, and to some extent large cotton plantation. The headwaters of the Simiyu River start at an elevation $1640 \mathrm{~m}$ a.s.l. The Simiyu River enters Lake Victoria at the Speke gulf at $1140 \mathrm{~m}$ a.s.l. The discharge of the Simiyu River is highly variable during the year =with a maximum discharge of about $208 \mathrm{~m}^{3} / \mathrm{s}$ during the long rainy season (March till May) and no flow during the dry season.

The Simiyu catchment was chosen as a case study for the hydrodynamic modeling of water and sediment flow, because it is considered to be one of the important contributors to the deterioration of Lake Victoria quality. Its relatively large catchment area (c. 10,800 $\mathrm{km}^{2}$ ) and its high yields of sediment due to the presence of agricultural activities and other sediment generating activities (Machiwa, 2002).

Bathymetric data were collected for seven cross sections, which were surveyed in 2004. The cross sections cover a reach of $15 \mathrm{~km}$ of the lower part of the stream channel, and the distance between the adjacent cross sections is approximately. Using the digital elevation model of the study area, additional cross sections were interpolated at an interval of 0.5 $\mathrm{km}$. Figure 2 shows some of the cross sections at downstream, middle and upstream of the study section. In this study, stream flow and sediment transport during a normal flood event during the long rainy season was used. Figure 3 gives the discharge and the corresponding sediment concentration during the typical flood event. Figure 4 is the water levels downstream. 


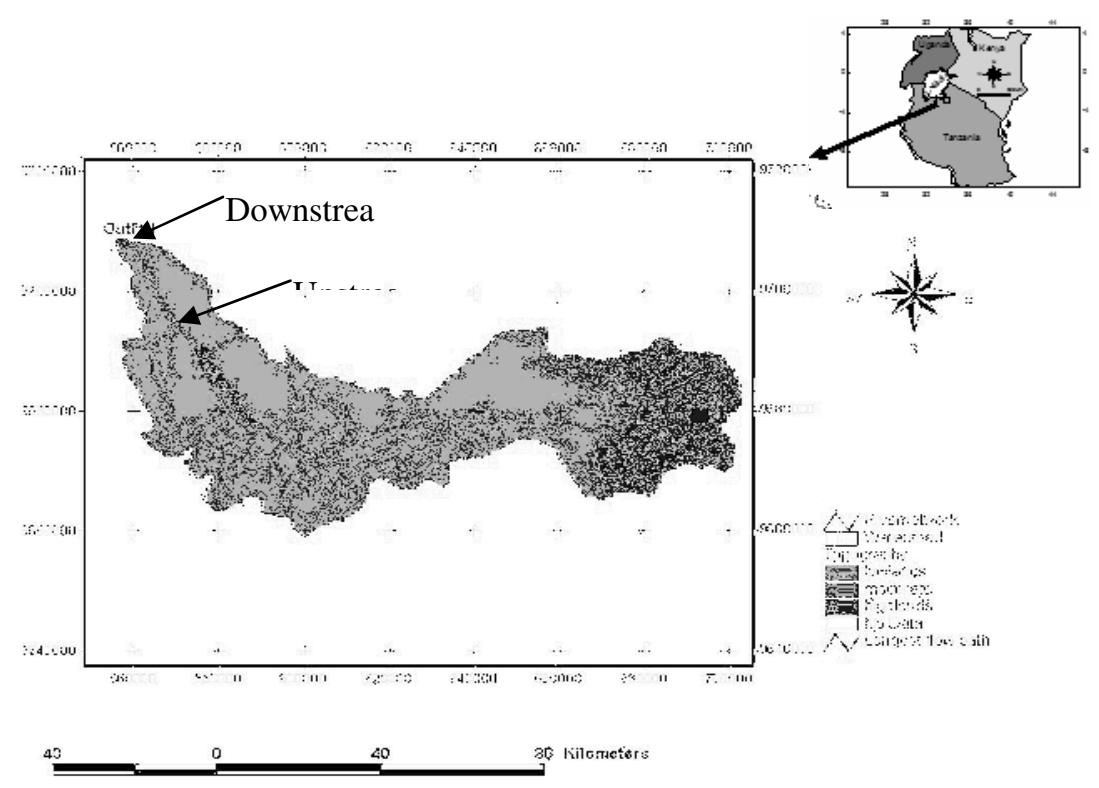

Figure 1 Location of Simiyu Catchment
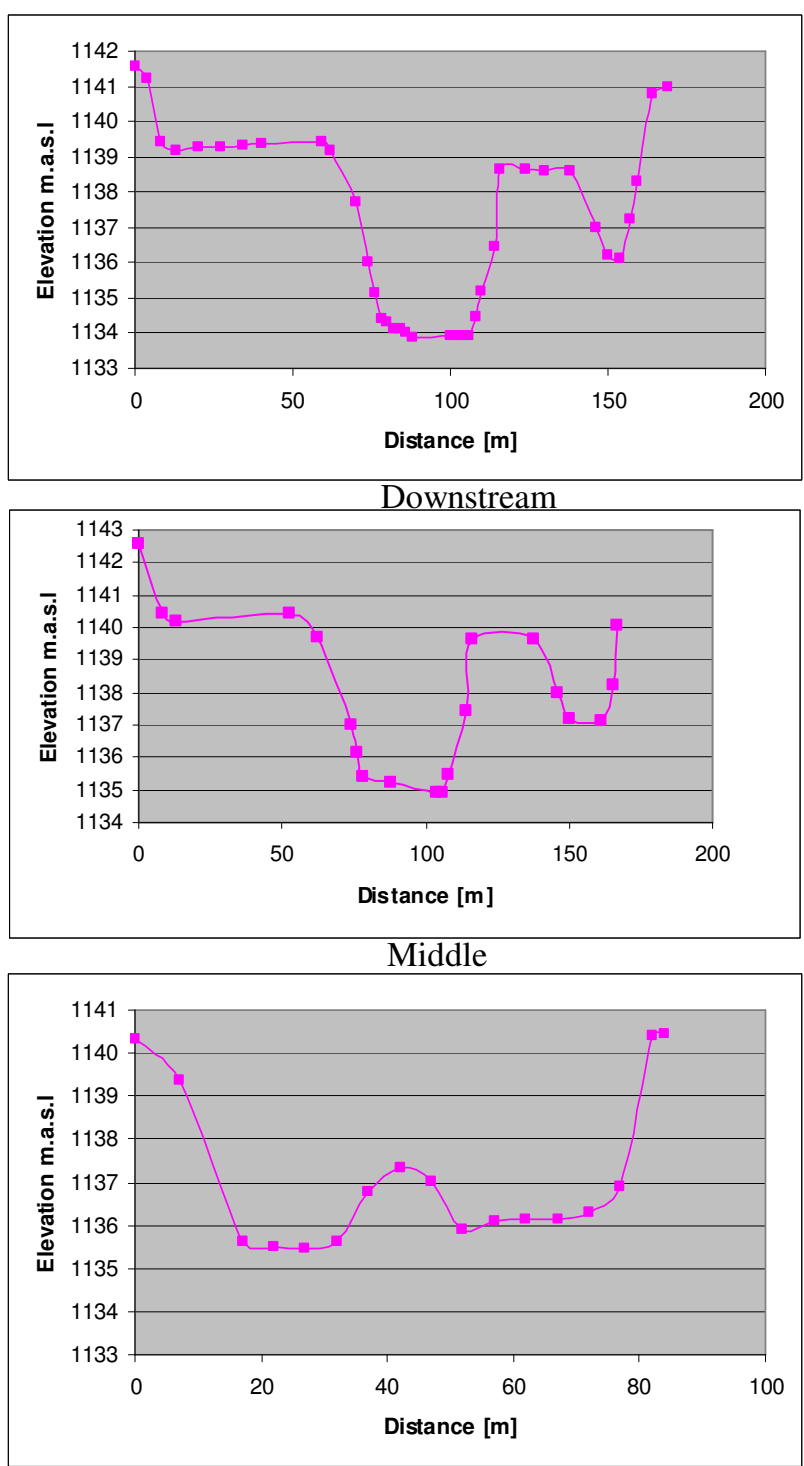

Upstream

Figure 2. Selected downstream, mid and upstream cross sections 


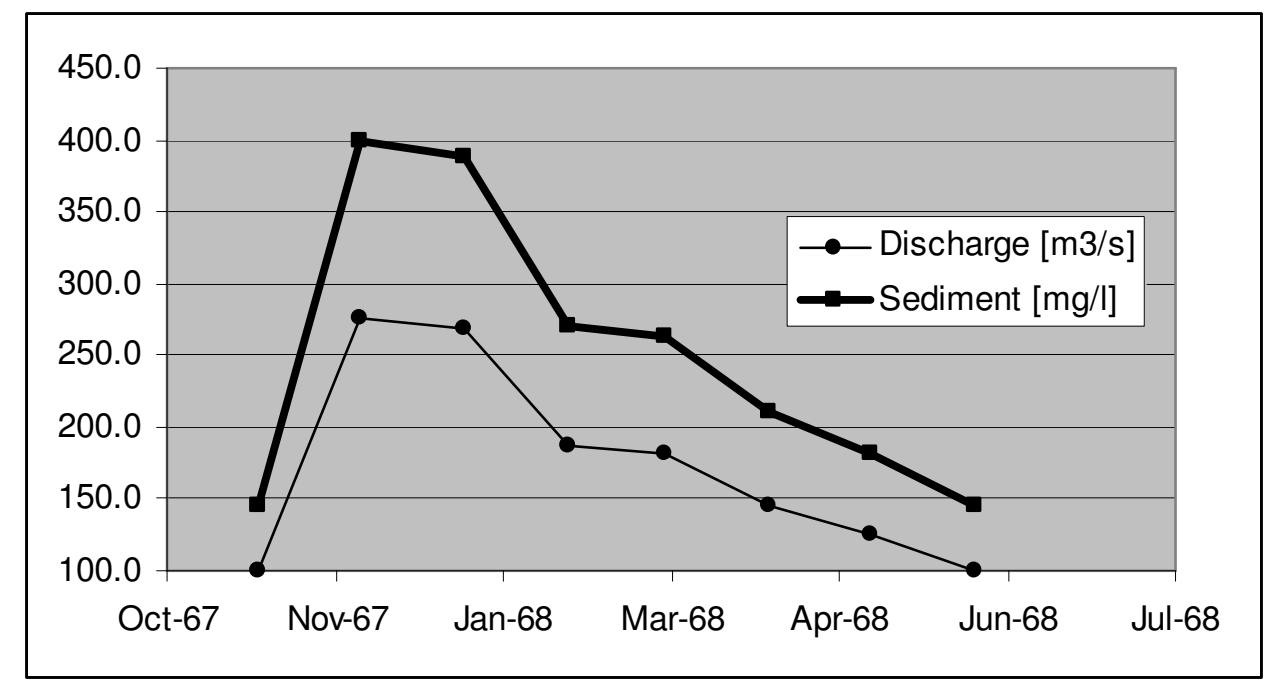

Figure 3: Typical flood discharge event and the corresponding suspended sediment concentration at the upstream boundary condition

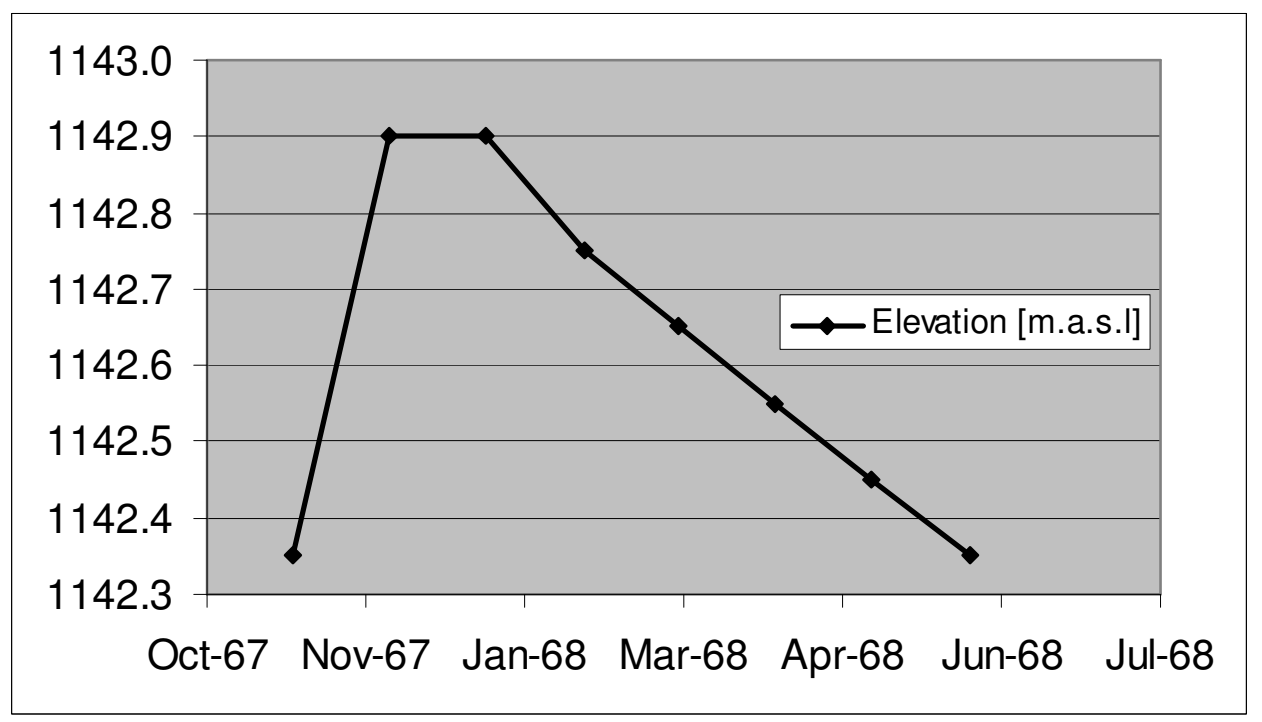

Figure 4: Water level downstream boundary condition of Simiyu River

\section{SMS MODEL}

Surface-Water Modeling System (SMS) is a comprehensive environment for 1D, 2D, and $3 \mathrm{D}$ hydrodynamic modeling. It is a pre- and post-processor for surface water modeling and design. SMS includes 2D finite-element, 2D finite-difference, 3D finite-element and 1D backwater modeling tools. A number of models are supported under SMS. Among these are the RMA2 for hydrodynamic and SED2D for sediment transport.

The numeric models supported in SMS compute a variety of information applicable to surface-water modeling. Primary applications of the models include calculation of water surface elevations and flow velocities for shallow water flow problems for both steadystate or dynamic conditions. The SED2D computes the sediment variables and processes eg score and deposition. SED2D model has the ability to compute sediment loadings and bed elevation changes when supplied with a hydrodynamic solution computed by RMA2. The model was applied to the lower reaches of Simiyu River to simulate the sediment transport in the river channel. 
The generalized computer program RMA2 solves the depth-integrated equations of fluid mass and momentum conservation in two horizontal directions. The equations are solved by the finite element method using the Galerkin method of weighted residuals (SMS user manual, 1998).

\section{SCALDIS MODEL}

SCALDIS is also a two dimensional depth averaged model consisting of a hydrodynamic module, a salt transport module, and a sediment transport module, allowing simulation of flow and transport processes in rivers, estuaries and coastal waters (Mwanuzi and De Smedt, 1997; Mwanuzi, 1998). It is coded in FORTRAN 77 and based on the finite volume method to solve the governing flow and transport equations. The method allows irregular computational meshes composed of triangular and quadrilateral cells, giving sufficient flexibility to represent complex geometry and bottom morphology. The hydrodynamic model calculates flow variables as water levels, velocities and discharges, while the salt transport module gives insight in estuarine mixing processes as dispersion. These results are used as inputs to the sediment transport module. The model also provides for graphic visualization of simulation outputs during run time. The following are the governing equations applied and solved by the model.

The model also solved the depth averaged hydrodynamic and transport equation using the finite volume numerical techniques by predictor corrector method in time advancement.

\section{RESULTS}

\section{SMS MODEL RESULTS}

First, a mesh was created for the $15-\mathrm{km}$ long river section using the measured cross sections and additional information from the digital elevation model of the area and the delineation of the river reach (Figure 5). The model is able to extrapolate the bathymetry/cross sections at all other location. The interpolated model depths are compared with measured depth in Figure 6 and they show a good agreement when superimposed which means the model is using correct cross sections at all of the locations. For dynamic flow simulation, SMS requires to simulate the initial steady state then the output is used as hotstart in the dynamic state. The hydrodynamic model was then run to simulate the stream flow under steady state and later under dynamic state. The output of the hydrodynamic module with time series of discharge and sediment loads, which correspond to a typical flood scenario during the flood event, was used for the simulation of the dynamic state. Figure 7 shows the water depth and the stream velocities at the peak of the flood event

The results of the sediment transport during the peak of the flood event are shown in Figure 8 . From the figure, it is clear that the shallow areas like flood plains are more depositing than main river channel. Bed changes are more pronounced in the upstream closer to the sediment input to the system (Figure 9). Downstream shows less deposition meaning longer time is required for the sediment to travel up to the downstream. 


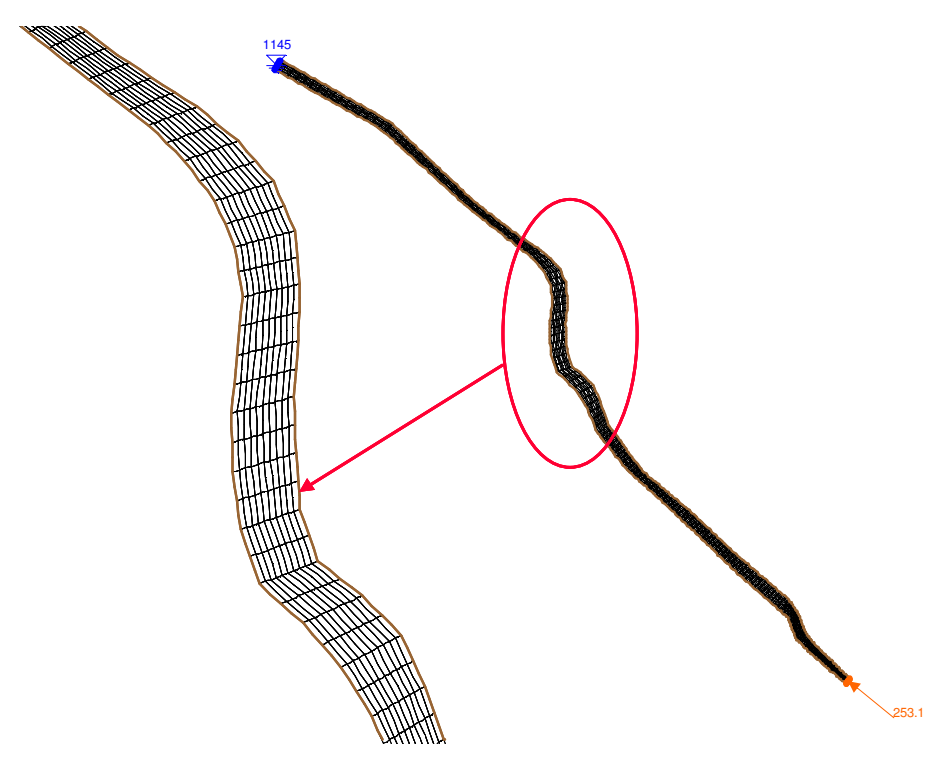

Figure 5 Mesh decartelization as applied to SMS

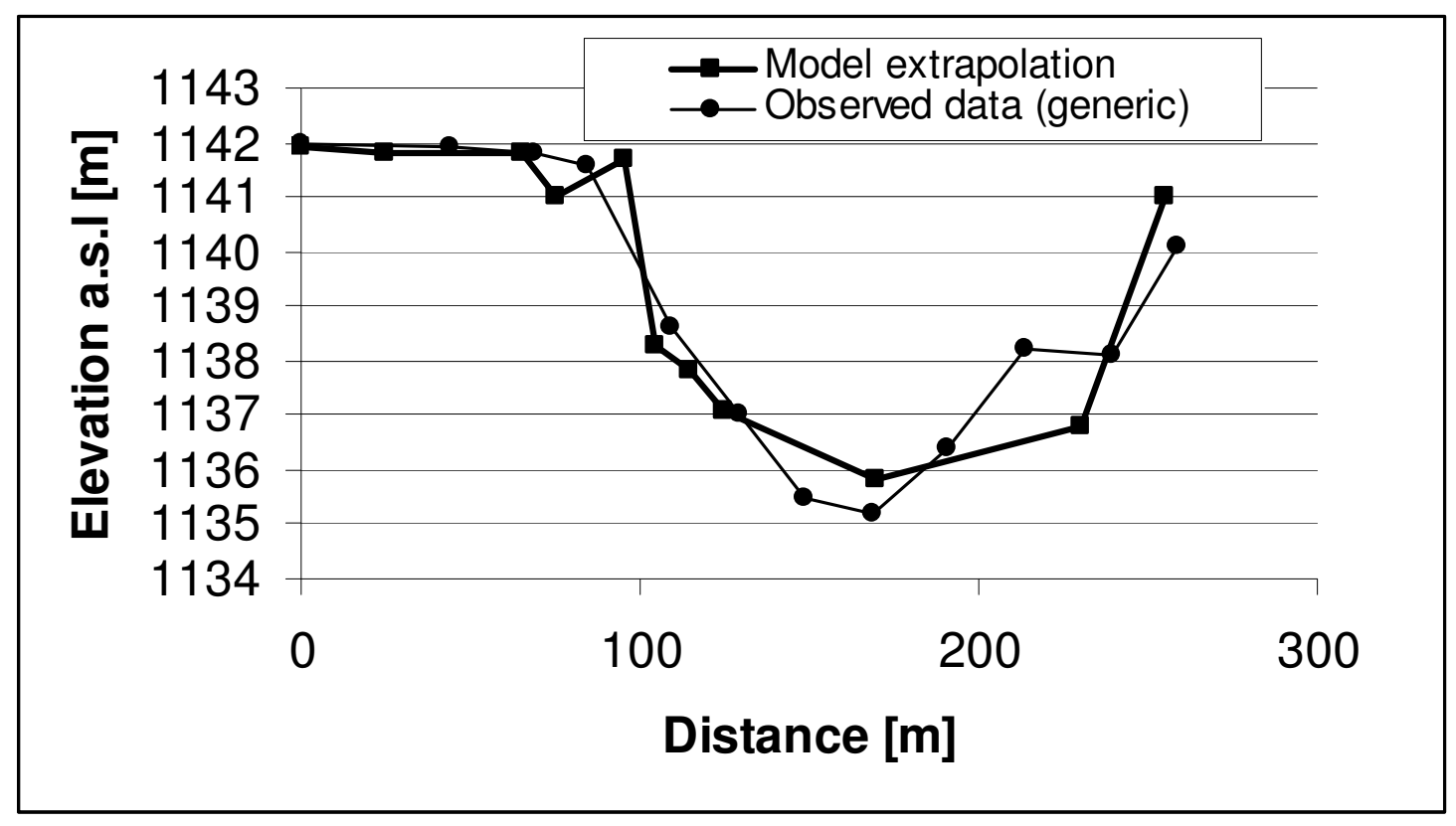

Figure 6 Measured cross section and interpolated cross section at a selected location 


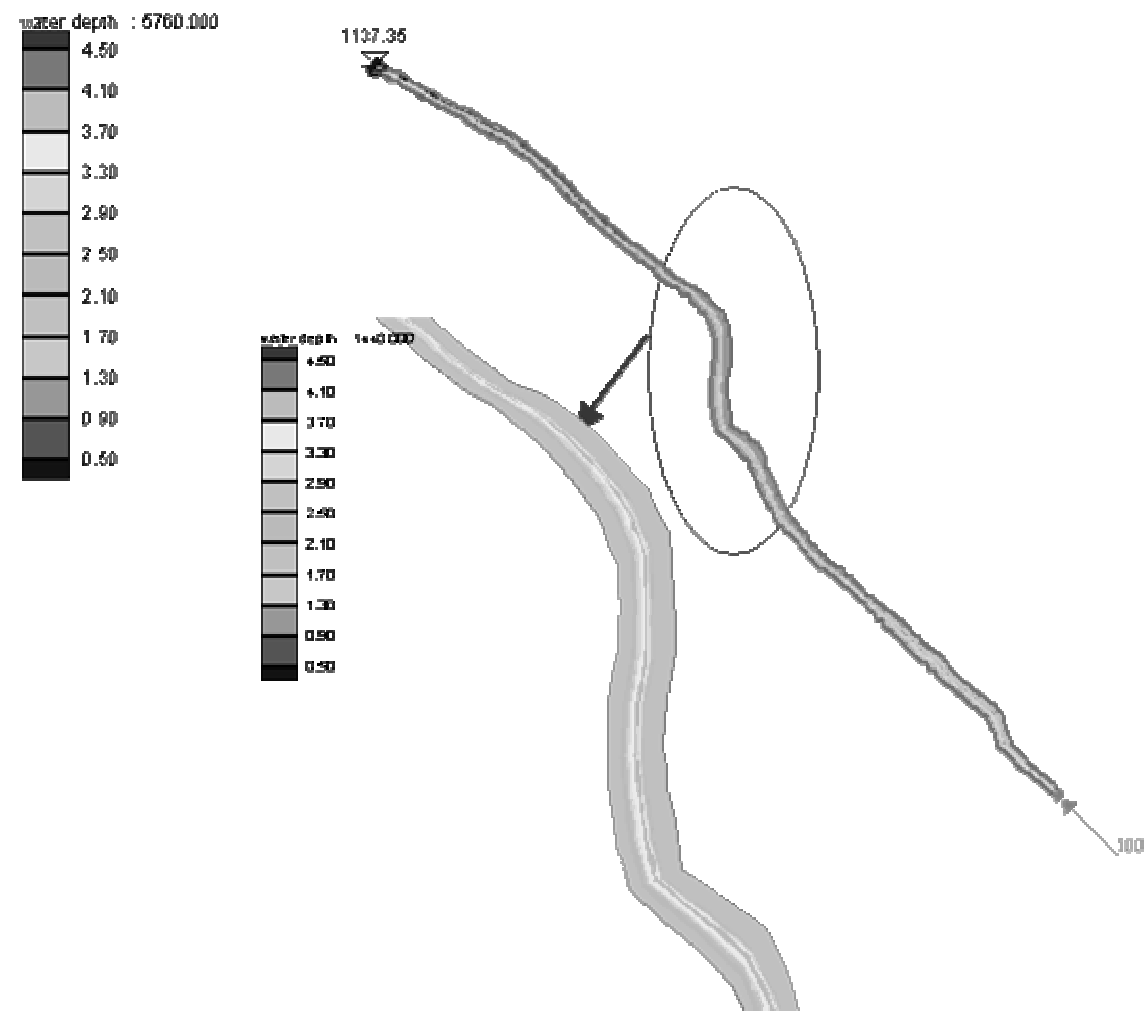

Figure 7a Steady state SMS output showing water depths
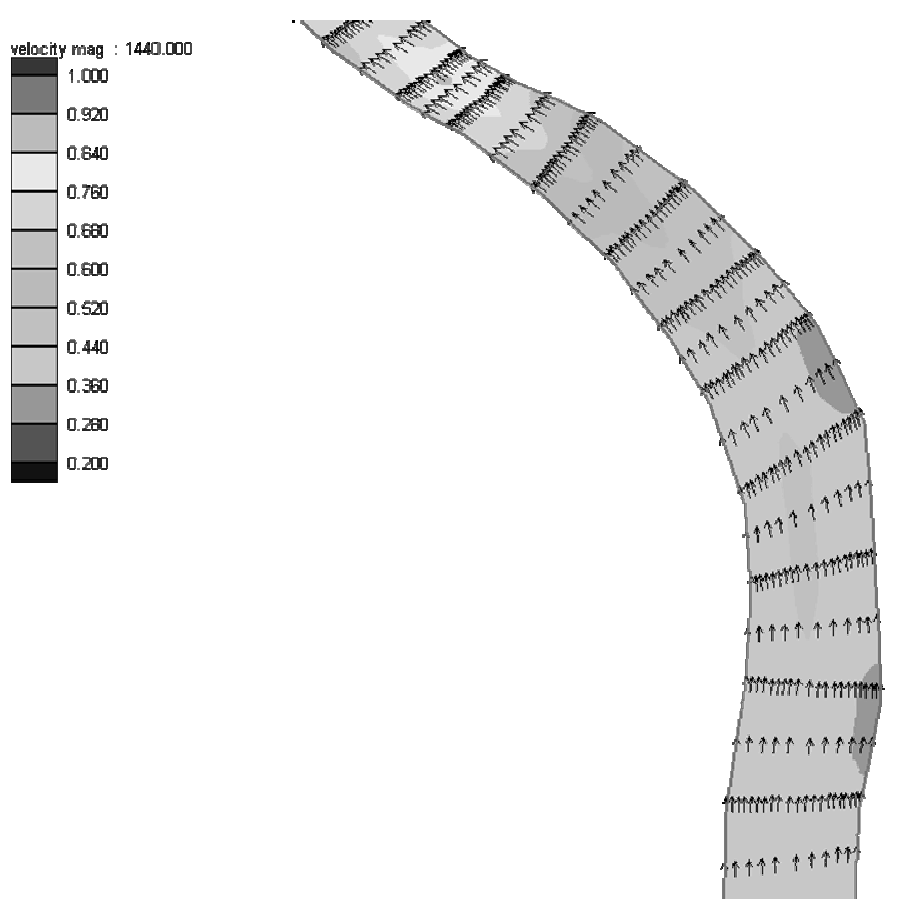

Figure $7 \mathrm{~b}$ SMS output showing velocity vectors 

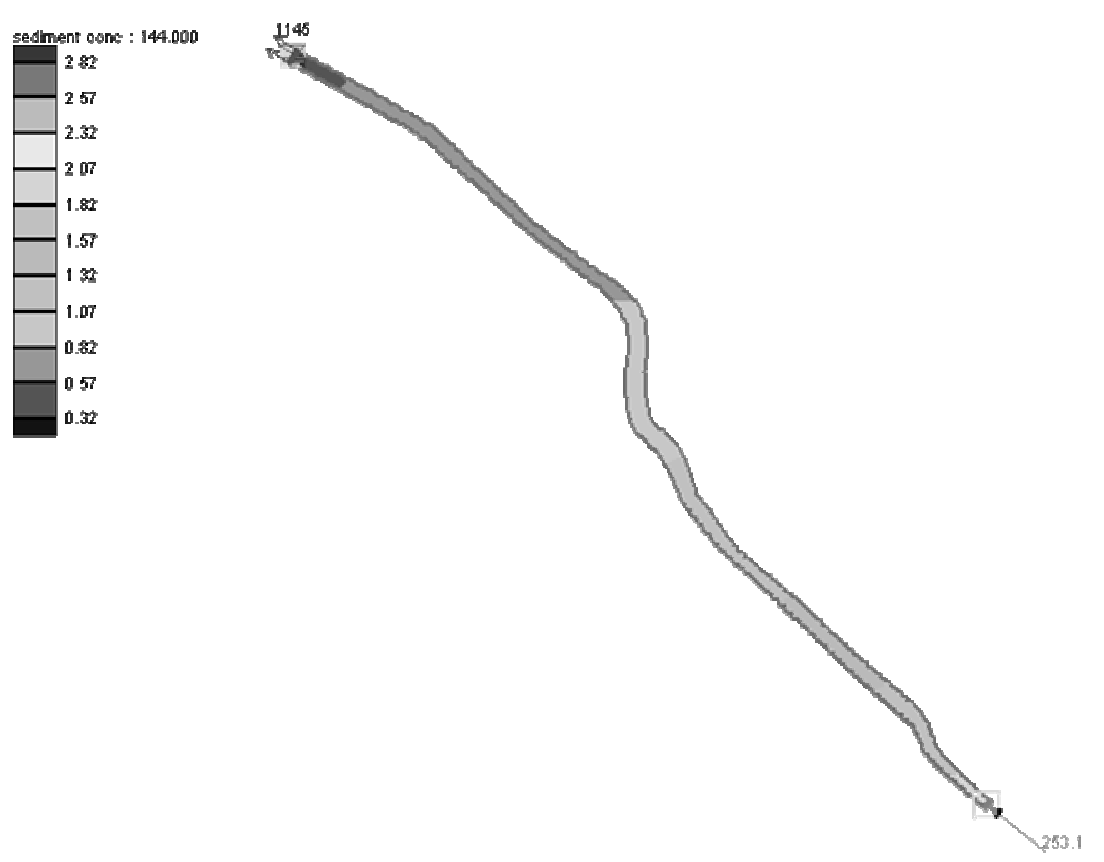

Figure 8. Sediment concentration after 144000 hours of simulation

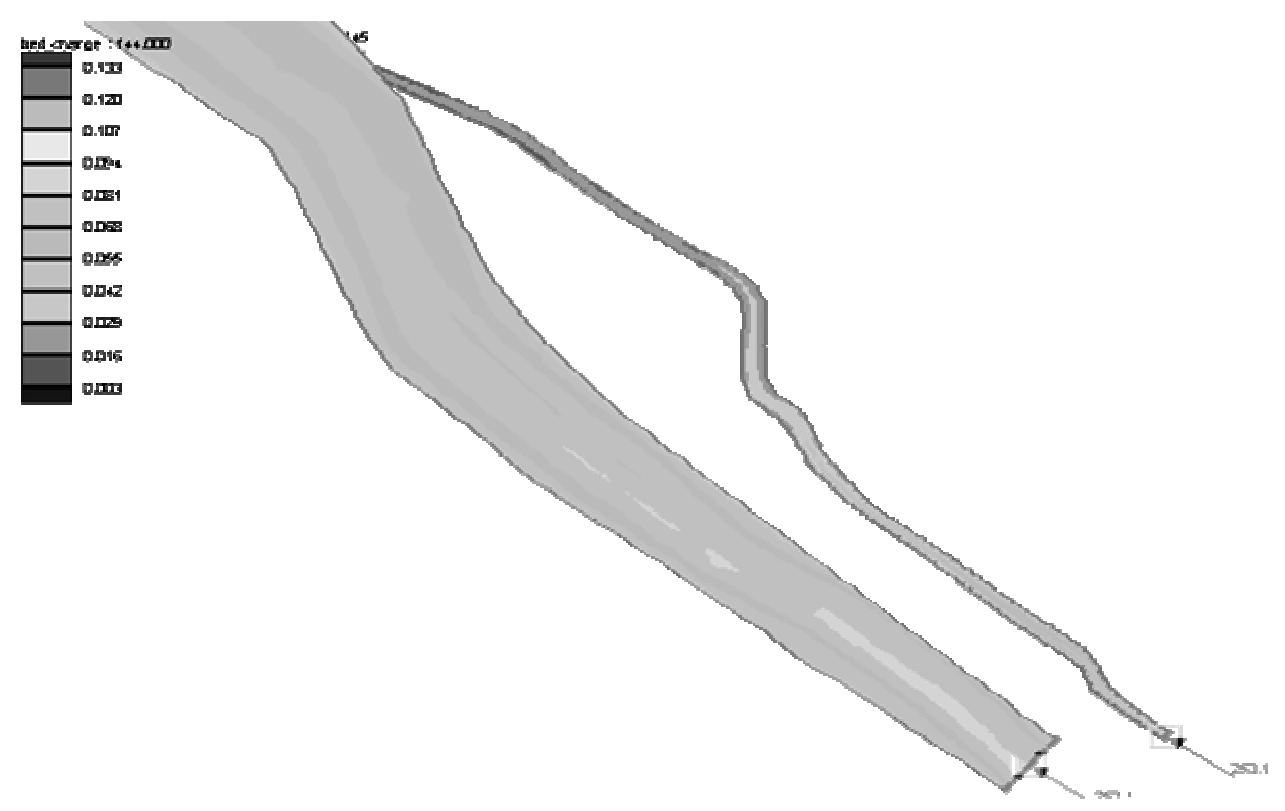

Figure 9a. Bottom bed change in $\mathrm{kg} / \mathrm{m}^{2}$ after 144000 hours of simulation 


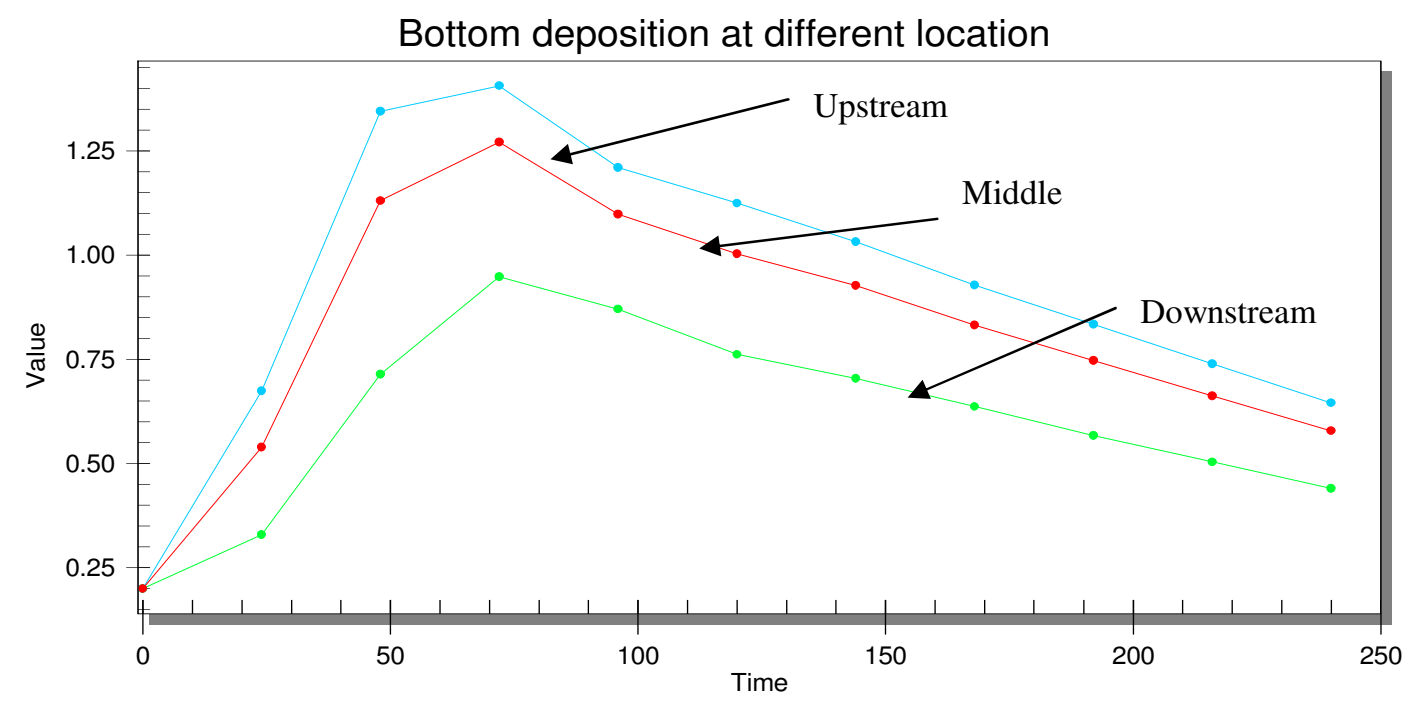

Figure $9 b$ Bed changes at different locations value in $\mathrm{kg} / \mathrm{m}^{2}$

\section{SCALDIS MODEL RESULTS}

The SCALDIS model was also applied to the lower reaches of the Simiyu river. Figure 10 shows the schematization of the lower part with the quadrilateral mesh as an input to SCALDIS. This mesh was schematized into 45 elements with 64 nodes. Figure 11 gives a snap shop during the model run time displaying the water levels at the peak of the simulated flood. The output of the model includes all abiotic parameters i.e. the average value for water levels, velocities, water depth (hydraulic radius), actual water width, bottom shear stress, and sediment flux. Figure 12 shows the sediment concentrations simulated by SCALDIS

From the SCALDIS model results it can be seen that there is clearly more deposition in the main river channel (Figure 13). Most of the time, the flood plains are dry and sediment is only deposited during flood events. Spatial analysis of simulated sediment deposition results indicated that the mean deposition in the shallow parts of the river channel and flood plains exceeded that of other locations. The simulated mass depositions per area for these sections were compared with deposition rate in other sections.

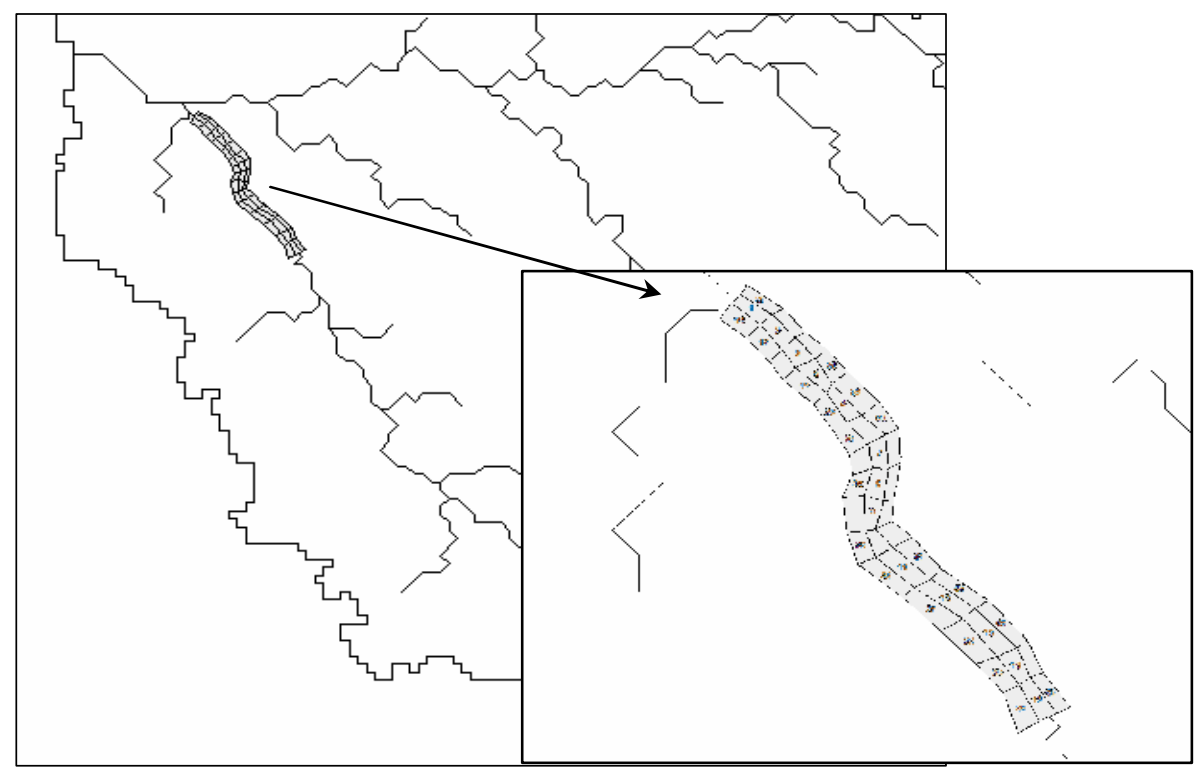

Figure 10 Schematization for SCALDIS application: 
* SCALDIS *

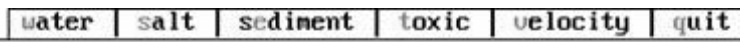

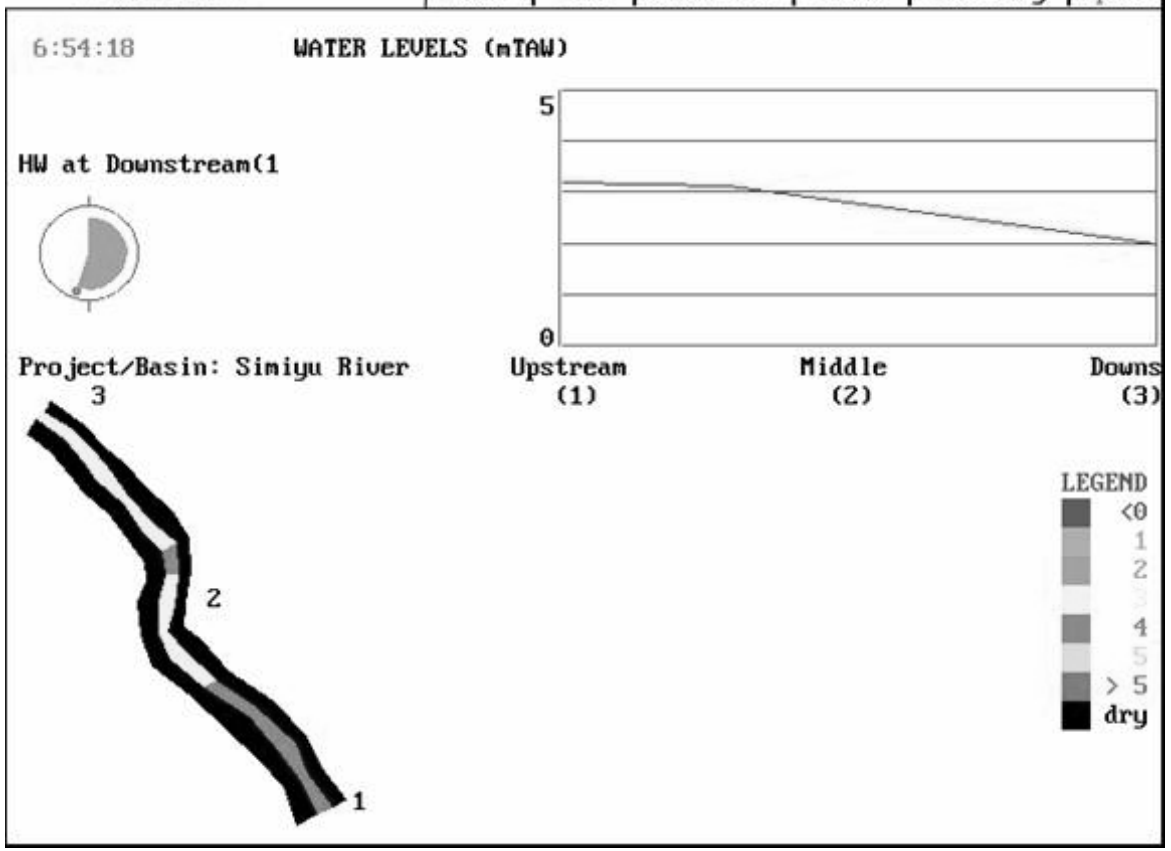

Figure 11 Snapshot during SCALDIS run time showing water levels in $\mathrm{m}$ above datum

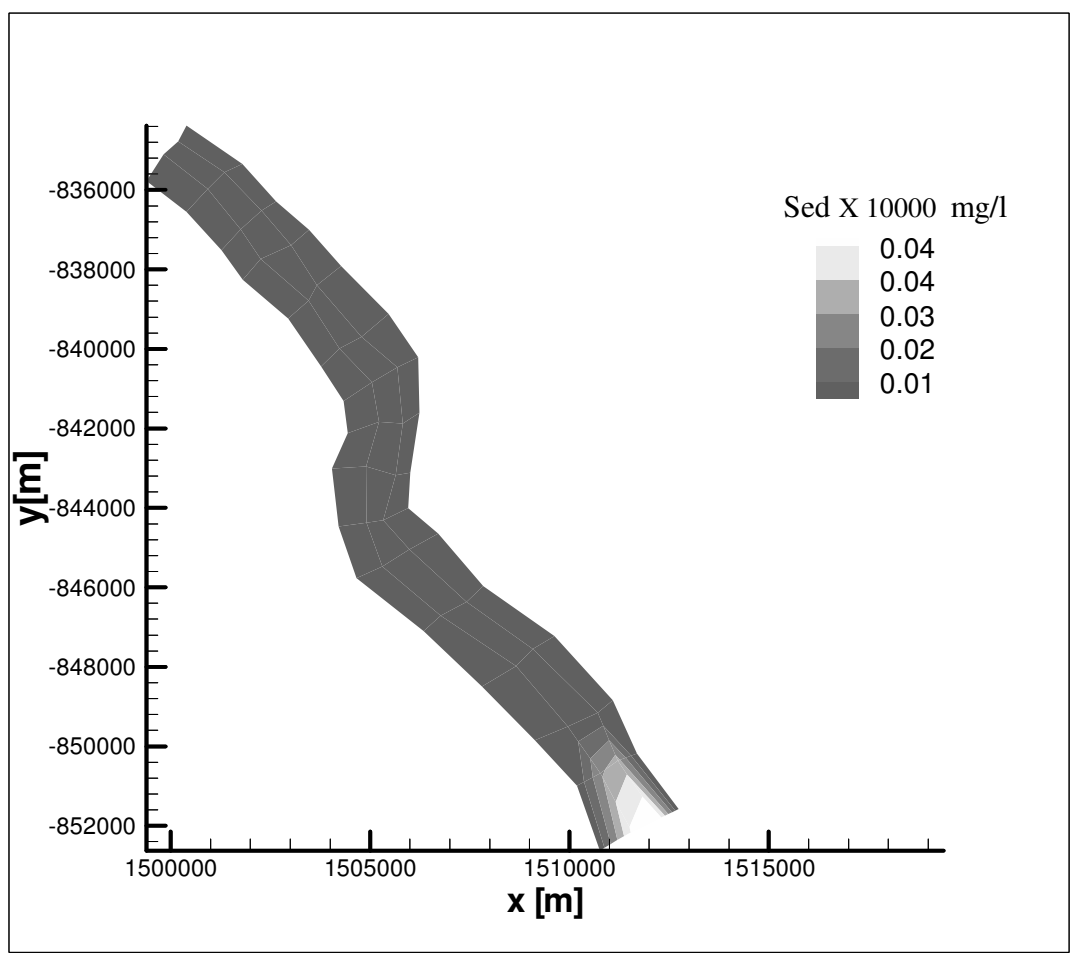

Figure 12 Sediment concentration output from SCALDIS 


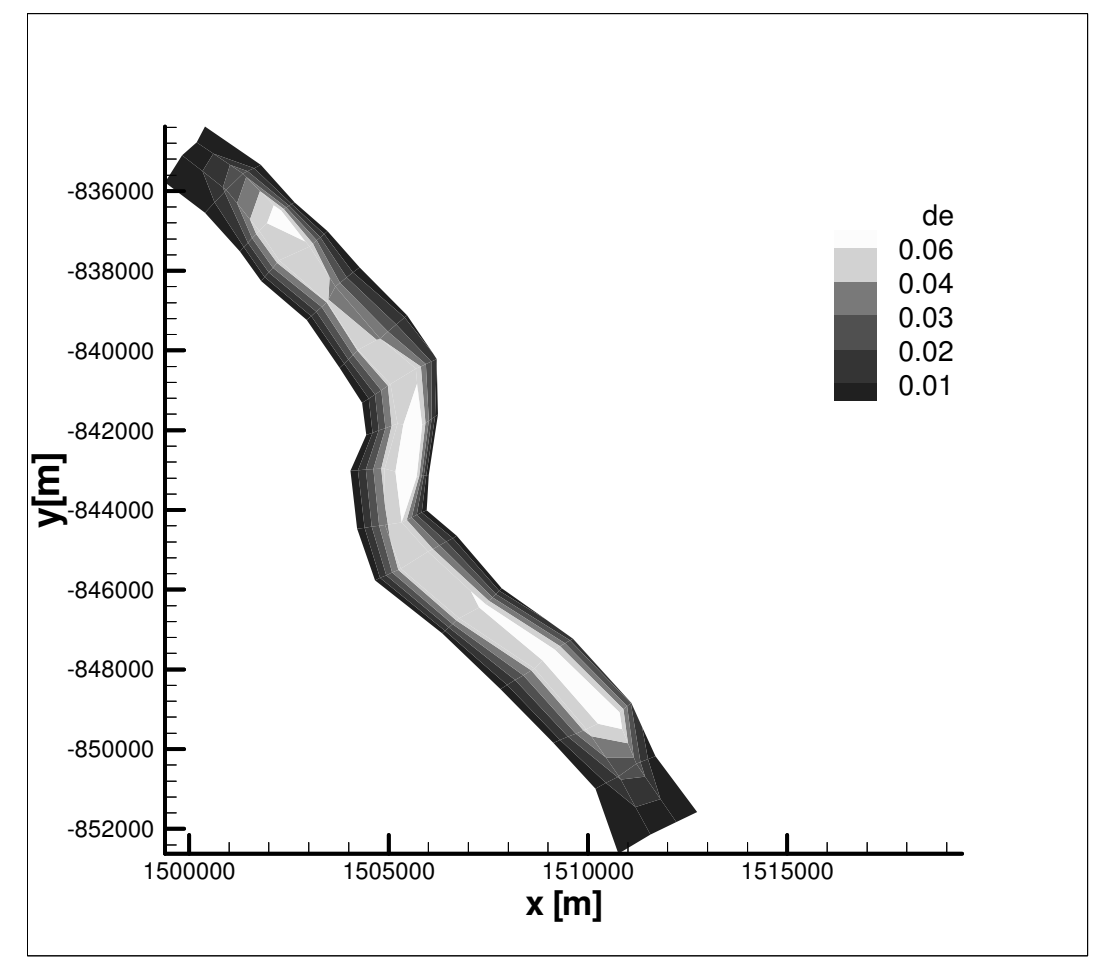

Figure 13 Bottom deposition (de in $\mathrm{kg} / \mathrm{m}^{2}$ ) simulated by SCALDIS

\section{DISCUSSION}

From the results it can be seem that SMS is applied successfully to the Simiyu river. The major controlling factors were the eddy viscosity and Manning's. Values of 5000 and 0.025 respectively produced the comparable results. These two most tuning parameters are not so easy to estimate thus it is by trial and error. To be able to run SMS-RMA2 it was required to use downstream water level above the highest bathymetry. This is only correct in flood plains and flatter rivers ie. Not on steep rivers. The hydrodynamic model is not coupled to transport module thus it generates a number of outputs which have to be stored in the computer before the transport module is run. The model equations are solved by the finite element method using the Galerkin method of weighted residuals.

For SCALDIS model the only sensitive parameter is the Manning's coefficient which calibrates the hydrodynamic module. Depending on the sediment type the critical shear stresses for erosion and sedimentation affected the amount of sedimentation and erosion in the study area. The model is based on finite element numerical techniques and is coupled to transport module thus less computer storage of data is required

Both model results indicate that the temporal variability of total sediment deposition during a flood event was strongly tied to the sediment inflow concentrations since at the upstream sections there is more sedimentation when compared to the downstream sections. Sediment deposition average of $0.02 \mathrm{~kg} / \mathrm{m} 2$ were obtained and this correspond to literature values (Mwanuzi, 1998; Mwanuzi aand DeSmedt, 1997). The actual values of sedimentation can be verified if core sample can be taken at different time moments. The comparison of both model results indicates that SCALDIS easier to calibrate as compared with SMS based sediment transport. The SMS modules require detailed information about a large number of model parameters, which is difficult to obtain in remote areas. The SCALDIS model is less input demanding, and the only sensitive parameter is the Manning's coefficient, which can be estimated based on expert knowledge and limited field measurements. 


\section{CONCLUSION}

Both models the SMS sediment module and SCALDIS can simulate sediment transport in the Simiyu river channel. Both models were calibrated using the typical flood event of 1968 and gave the same order of sediment deposition magnitude with an average of $0.02 \mathrm{~kg} / \mathrm{m}^{2}$ in the period of 4 months. However the application of SMS required a number of tuning parameters such as eddy viscosity, which is not so easy to estimate. For SCALDIS model the only sensitive parameter was the Manning's coefficient. .SCALDIS model is coupled and thus require less computer storage when compared to SMS. Both models need to be run for a longer periods so as to determine the amount of sediments which will deposit in different locations and the application will require the second set of data so as to validate the selected model.

\section{ACKNOWLEDGMENTS}

This paper presents the results of a study conducted by the FRIEND/NILE research component on sediment and watershed management. The study was financed by UNESCO/UDSM collaboration.

\section{REFERENCES}

American society of Civil Engineers, ASCE. Sedimentation Engineering. Manuals of Engineering practice-No.54. 745p. 1975.
Emmanuel. D.P. Suspended sediment simulation model for Pangani River. M.Sc. Thesis, Faculty of Engineering, University of Dar es salaam. 15-22p. 2000.

Garde, R.J., and Ranga Raju, K.G. Mechanics of sediment transport and alluvial streams problems \{Second edition). 618p. 1977.

Tilrem, A.O. Sediment transport in streams sampling, analysis and computation. Manual1979.

Machiwa, F. (ed). Nutrients, micro-algae, sedimentation and sediment associations at the mouth of Simiyu river (Magu bay of Speke gulf) Lake Victoria, Tanzania. A report submitted to LVEMP, Tanzania,2002.

Mwanuzi, F. Modelling of Toxic pollutants Transport in an Estuarine Environment PhD. Thesis, Free University of Brussels, Belgium, 1998

Mwanuzi, F. and De Smedt, F. A suspended sediment transport model applied to the Scheldt estuary. Pro. 9th Int. Conf. On Transport and sedimentation of solid particles,. Cracow Poland: 285-296, 1997. 2-5 September 1997.

Van Leussen, W. Sediment Transport Under Tidal Action, Geo-Marine Letters, pp 119126, Springer - Verlag, New York. 1991. 